\title{
COVID-19 pandemic impact on headache in healthcare workers: a narrative review
}

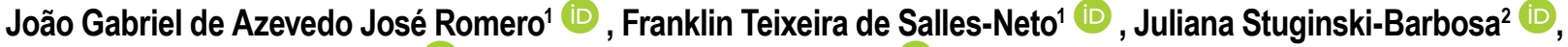 \\ Paulo César Rodrigues Conti ${ }^{2}$ (D) , Camila Megale Almeida-Leite ${ }^{2}$ (D)
}

${ }^{1}$ Universidade Federal de Minas Gerais, Belo Horizonte, MG, Brazil;

${ }^{2}$ Universidade de São Paulo, Bauru, São Paulo, Brazil

\section{$凶$}

Camila Megale Almeida-Leite Laboratório de neurobiologia Conceição Machado/O3-245 Departamento de Morfologia, Instituto de Ciências Biológicas (ICB), Universidade Federal de Minas Gerais (UFMG), Av. Antônio Carlos, 6627 - Pampulha - $31290-701$

Belo Horizonte/MG - Brazil camila@icb.ufmg.br

Edited by:

Marcelo Moraes Valença

Keywords:

Coronavirus infections

Headache

COVID-19

Healthcare workers

Personal protective equipment

\begin{abstract}
Background

Pandemic of COVID-19, the potentially fatal disease caused by SARS-CoV-2, had caused intangible consequences on global health systems, economy, daily life, education, travel, leisure, work, and mental health. Its impact on mental and physical health, especially in health professionals, has been described.

\section{Objective}

This study aimed to review and discuss the published evidence regarding the presence of headache on COVID-19 healthcare workers.

Methods

In this review, we searched for all articles published in various databases including PubMed/ Medline, Scopus, and Web of Science and all original research studies, letters to editor, case reports, commentaries and reviews published in English, Portuguese or Spanish were searched. Two researchers independently analyzed published articles in order to include/ exclude based on inclusion or exclusion criteria.

Results

Thirteen articles were included. All studies included in this review were observational; eleven were cross-sectional studies, one was a prospective/cohort and one was a retrospective. Two studies evaluated psychological outcomes, mental health disorders and associated factors, one study investigated symptoms and causes of somatic symptom disorder and all other studies evaluated headaches associated with personal protective equipment.

\section{Conclusions}

The present review shows that COVID-19 pandemic has negative impact on physical and mental health in healthcare workers and headache has been associated with psychological stress and work overload during pandemic. Further studies are necessary to better investigate COVID-19 pandemic effects on headaches and other neurological conditions.
\end{abstract}




\section{Introduction}

n December 2019, several cases of pneumonia of unknown etiology in Wuhan, China, had been announced and a new-type of coronavirus, named SARS-CoV-2, was confirmed as the cause of the outbreak. ${ }^{1}$ COVID-19, the potentially fatal disease caused by SARS-CoV-2, had become an emergency of international concern. ${ }^{2}$ Transmission occurs from human to human, mainly by direct contact or droplets spread by cough or sneeze of an infected person. ${ }^{2}$ Social isolation to prevent COVID-19 spread and the disease itself have caused intangible consequences on global health systems, economy, daily life, education, travel, leisure, work, and mental health. ${ }^{3 \cdot 5}$

COVID-19 pandemic has had a massive impact on frontline healthcare workers due to heavy workload with increased hours, increased number of patients to treat, including those with risk of death, a higher possibility of exposure to the virus, associated with a scarcity of health supplies and resources, especially in poor and developing countries. In addition, frequent deaths of patients and coworkers and a high level of concern about exposing family members to the disease are contributing factors to this scenario. It is well known that stressors at workplace affect employee's physical and mental health and symptoms may arise. ${ }^{6,7}$ In addition, an increased drive towards the use of personal protective equipment (PPE) to reduce infection is an additional factor that negatively impact healthcare professionals during COVID-19 pandemic. ${ }^{8}$

Based on this fact, different manifestations of health-related problems are expected in this population, including physical, somatic and behavioral diseases. Headache is commonly related to stress, depression, anxiety and other mental disorders. Psychiatric comorbidities have been commonly observed in patients with primary headaches as migraine and the tension-type headache (TTH) ${ }^{9.11}$ The relationship between migraine and psychiatric disorders such as depression and anxiety is well established and bidirectional. ${ }^{12.14}$ People with migraine are more likely to suffer from depression or anxiety and patients with depression or anxiety are more likely to have migraine. ${ }^{12,15}$ Similarly, concomitant presence of psychiatric disorders in patients with migraine or TTH is associated with increased headache frequency, acute medication overuse, progression to chronicity, and poor prognosis. ${ }^{13,16}$ Moreover, it has been shown that the excessive usage of respiratory (masks) and eye (glasses) protection tools may also increase the risk of headaches. ${ }^{1721}$ Hence, it is expected that during the COVID-19 pandemic, the association of psychiatric issues, such as moderate to very-severe depression, anxiety, and stress, with physical factors, as the use of protective equipment, create a perfect scenario for the increased frequency of headache in healthcare workers. ${ }^{22}$ Symptoms of dyspnea, chest discomfort and palpitation, headache, and fatigue have also been described. ${ }^{6}$

Given the importance of this recent issue, the present study aimed to review and discuss the published evidence regarding the presence of headache on COVID-19 healthcare workers.

\section{Methods}

\section{Study design}

This is a narrative review designed to collect and discuss published literature on COVID-19 pandemic effects on headache in healthcare workers. The following steps were followed to conduct the study: (1) identification of a clear research objective and search strategies, (2) identification and selection of relevant research articles, (3) extraction and charting of data, and (4) summary, discussion, and report of results.

\section{Literature search strategies}

In this review, we searched for all articles published in various databases including PubMed/Medline, Scopus, and Web of Science, using keywords "covid 19", "SARSCoV-2", "pain", "facial pain", "headache", "healthcare workers", "dentists", "physicians", and "nurses". All original research studies, letters to editor, case reports, commentaries and reviews published in English, Portuguese or Spanish were searched without time limit.

\section{Identification and selection of relevant studies}

Two researchers (FTSN and JGAJR) independently analyzed title and abstract of all published articles. Disagreements regarding inclusion or exclusion of articles were solved through discussion. Duplicate articles were eliminated.

\section{Data extraction from included studies and summary of the findings}

After selection of the articles, full text was obtained for all articles and were read by the two reviewers, who extracted all potentially relevant data. All findings were arranged in a data summary table. The data chart included author(s), 
year of publication, study location, intervention type/study type, comparator (if any), duration of the intervention, study populations, aims of the study, methodology, outcome measures, important results. Based on the main research objective, collected information was summarized, discussed and reported.

\section{Results}

\section{Characteristics of included studies}

Table 1. Studies included in the review.

\begin{tabular}{|c|c|c|c|c|}
\hline Authors & Study Location & Study type & Aims of the study & Important results \\
\hline Chew et al., ${ }^{22}$ & $\begin{array}{l}\text { Singapore } \\
\text { and India }\end{array}$ & $\begin{array}{l}\text { Observational/ } \\
\text { Cross-sectional } \\
\text { study }\end{array}$ & $\begin{array}{l}\text { To associate psychological outcomes and } \\
\text { physical symptoms among healthcare } \\
\text { workers. }\end{array}$ & $\begin{array}{l}\text { Depression }(p=0.001) \text {, anxiety }(p=0.001) \text {, stress }(p=0.13) \text {, and PTSD } \\
(p=0.023) \text { were significantly associated with the presence of physical } \\
\text { symptoms. Most common physical symptom. }\end{array}$ \\
\hline Yifan et al., ${ }^{6}$ & China & $\begin{array}{l}\text { Observational / } \\
\text { Cross-sectional } \\
\text { study }\end{array}$ & $\begin{array}{l}\text { To investigate symptoms and causes of } \\
\text { SSD of ICU nurses treating COVID-19 } \\
\text { pneumonia. }\end{array}$ & $\begin{array}{c}\text { The } 5 \text { most severe symptoms were dyspnea, chest discomfort and } \\
\text { palpitation, headache, fatigue, and xerostomia. }\end{array}$ \\
\hline Ong et al., ${ }^{17}$ & Singapore & $\begin{array}{l}\text { Observational / } \\
\text { Cross-sectional } \\
\text { study }\end{array}$ & $\begin{array}{l}\text { To determine risk factors associated with } \\
\text { the development of de novo PPE-associated } \\
\text { headaches and the perceived impact of } \\
\text { these headaches on personal health and } \\
\text { work performance in healthcare workers. }\end{array}$ & $\begin{array}{c}\text { Participants with a pre-existing primary headache diagnosis ( } p=0.013 \text { ) } \\
\text { and combined PPE usage for }>4 \text { hours per day }(p=0.012) \text { were more } \\
\text { likely to develop de novo PPE-associated headaches. }\end{array}$ \\
\hline Tabah et al., ${ }^{18}$ & $\begin{array}{l}\text { Many } \\
\text { Countries }\end{array}$ & $\begin{array}{l}\text { Observational / } \\
\text { Cross-sectional } \\
\text { study }\end{array}$ & $\begin{array}{l}\text { To describe current reported practices, } \\
\text { availability, training, confidence in use and } \\
\text { adverse effects due to the prolonged use of } \\
\text { PPE by healthcare professionals around the } \\
\text { world caring for COVIDI9. }\end{array}$ & 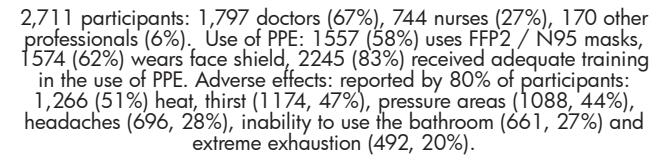 \\
\hline Sharif et al., ${ }^{19}$ & $\begin{array}{l}\text { Many } \\
\text { Countries }\end{array}$ & $\begin{array}{l}\text { Observational / } \\
\text { Cross-sectional } \\
\text { study }\end{array}$ & $\begin{array}{l}\text { To assess stressors as a result of the } \\
\text { pandemic; determine the prevalence } \\
\text { and factors associated with anxiety and } \\
\text { depression; determine the frequency of } \\
\text { depression during the pandemic. }\end{array}$ & $\begin{array}{c}375 \text { guestionnaires answered : } 52 \text { countries; } 34 \% \text { with increased tension, } \\
32.5 \% \text { unhappy, } 25 \% \text { with insomnia, } 20 \% \text { with headache and } 5 \% \\
\text { with suicidal ideation; } 14 \% \text { of participants had scores consistent with } \\
\text { depression; probability of depression was greater in professionals who } \\
\text { did not receive adequate guidance on the use of PPE. }\end{array}$ \\
\hline $\begin{array}{l}\text { Bharatenduet } \\
\text { et al., }{ }^{20}\end{array}$ & Singapore & $\begin{array}{l}\text { Observational / } \\
\text { Cross-sectional } \\
\text { study }\end{array}$ & $\begin{array}{l}\text { To evaluate cerebral hemodynamics during } \\
\text { the placement of the N95 respiratory mask } \\
\text { alone, as well as in conjunction with PAPR. }\end{array}$ & $\begin{array}{c}154 \text { health professionals: migraine headache was the most common } \\
\text { comorbidity } 38 \text { professionals } 25 \%) ; 123(80 \%) \text { developed headache } \\
\text { due to the use of the N95 mask; N95 and N95 + PAPR masks leads to } \\
\text { changes in cerebral hemodynamics. }\end{array}$ \\
\hline $\begin{array}{l}\text { Ramirez- } \\
\text { Moreno et } \\
\text { al., }{ }^{21}\end{array}$ & Spain & $\begin{array}{l}\text { Observational / } \\
\text { Cross-sectional } \\
\text { study }\end{array}$ & $\begin{array}{l}\text { To demonstrate whether there is an } \\
\text { association between the appearance of } \\
\text { "new" headache with the type of mask and } \\
\text { its duration of use, as well as the impact of } \\
\text { this headache. }\end{array}$ & $\begin{array}{l}306 \text { health professionals participated: Surgical mask used by } 208 \\
\text { (79.7\%), filter mask (N95 or FFP2) used by } 53(20.3 \%) \text { of the } \\
\text { professionals; } 158(51.6 \%) \text { reported the appearance of a new } \\
\text { headache, of which } 65(41.1 \%) \text { already had a headache (migraine or } \\
\text { tension), } 103(33.7 \%) \text { did not report a new headache. }\end{array}$ \\
\hline Haijii et al., ${ }^{23}$ & Marocco & $\begin{array}{l}\text { Observational / } \\
\text { Cross-sectional } \\
\text { study }\end{array}$ & $\begin{array}{l}\text { To describe headache subtypes among } \\
\text { frontline health professionals using PPE; } \\
\text { determine correlations between PPE-related } \\
\text { headaches, working conditions and trends } \\
\text { in PPE use. }\end{array}$ & $\begin{array}{l}155 \text { professionals answered the questionnaire: } 81 \text { (52.3\%) had previous } \\
\text { chronic headache and migraine was the most prevalent type in } 47 \\
(30.3 \%) ; 96(62 \%) \text { health professionals reported headache induced by } \\
\text { the use of PPE; } 41(32.9 \%) \text { headache as "new" headache and } 45(29 \%) \\
\text { considered it as already experienced but worsened by the use of PPE. }\end{array}$ \\
\hline $\begin{array}{l}\text { Swaminathan } \\
\text { et al., }\end{array}$ & $\begin{array}{l}\text { United } \\
\text { Kingdom }\end{array}$ & $\begin{array}{l}\text { Observational / } \\
\text { Cross-sectional } \\
\text { study }\end{array}$ & $\begin{array}{l}\text { To describe the impact of PPE and the effects } \\
\text { on the physical and mental well-being of } \\
\text { health professionals. }\end{array}$ & $\begin{array}{c}72 \text { questionnaires were answered: } 70.8 \% \text { reported exhaustion when } \\
\text { using PPE, } 61.7 \% \text { reported headache, } 90.3 \% \text { reported difficulty in } \\
\text { communication, } 47.3 \% \text { reported negative impact on performance, } 27.8 \% \\
\text { reported anxiety, } 19.5 \% \text { depression. }\end{array}$ \\
\hline Zaheer et al., ${ }^{24}$ & Pakistan & $\begin{array}{l}\text { Observational / } \\
\text { Cross-sectional } \\
\text { study }\end{array}$ & $\begin{array}{l}\text { To determine the association of the use of } \\
\text { PPE with headache of recent onset and } \\
\text { exacerbation of pre-existing headache } \\
\text { disorders. }\end{array}$ & $\begin{array}{l}241 \text { health professionals: } 68(28.2 \%) \text { reported headaches again; Of the } \\
68 \text { with recent onset headaches, } 16(23.5 \%) \text { the pain started more than } \\
2 \text { hours after PPE placement; while } 19(27.9 \%) \text { stated that the headache } \\
\text { ended within } 1.2 \text { hours after removing the PPE. }\end{array}$ \\
\hline $\begin{array}{l}\text { Choudhury et } \\
\text { al., }{ }^{26}\end{array}$ & India & $\begin{array}{l}\text { Prospective and } \\
\text { observational }\end{array}$ & $\begin{array}{l}\text { To evaluate the physiological effects and } \\
\text { the tolerability of the PPE kit together with } \\
\text { the N95 respirator in health professionals in } \\
\text { their daily routine activities in the ICU. }\end{array}$ & $\begin{array}{l}75 \text { health professionals: Significant difference in post-exchange } \\
\text { physiological parameters compared to baseline values: freguency } \\
\text { cardiac }(p<0.001) \text {; oxygen saturation }(p<0.001) \text {; PI ( } p<0.001) \text {. RPE } \\
\text { showed greater discomfort with the continuous use of N95 FFR. However, } \\
\text { the effort has increased only marginally. Adverse effects: fogging, } \\
\text { headache, tiredness, difficulty in breathing and imbibition of the mask. }\end{array}$ \\
\hline $\begin{array}{l}\text { Rapisarda et } \\
\text { al., }{ }^{25}\end{array}$ & Italy & $\begin{array}{l}\text { Observational / } \\
\text { Cross-sectional } \\
\text { study }\end{array}$ & $\begin{array}{l}\text { To examine headache variations related } \\
\text { to the intensive use of facial masks in } \\
\text { healthcare professionals in a low to medium } \\
\text { risk scenario of exposure to SARS-CoV-2. }\end{array}$ & $\begin{array}{l}400 \text { questionnaires: } 383 \text { validated: Of the } 166 \text { headache-free } \\
\text { individuals, } 44 \text { ( } 26.5 \%) \text { developed headache again; } 217 \text { reported } \\
\text { previous diagnosis of primary headache: } 137 \text { migraine and } 80 \text { tension- } \\
\text { type headache; } 31.3 \% \text { of those with primary headache experienced an } \\
\text { aggravation due to the frequency and average duration of the attack. }\end{array}$ \\
\hline $\begin{array}{l}\text { Shubhanshu } \\
\text { and Singh, }{ }^{27}\end{array}$ & India & Retrospective & $\begin{array}{l}\text { To evaluate the adverse effects of the use of } \\
\text { protective masks. }\end{array}$ & $\begin{array}{l}423 \text { participants: } 283(67 \%) \text { wore the N95 / } 140 \text { mask (33\%) wore the } \\
\text { surgical mask; Main complaints: } 23 \% \text { headache / } 22 \% \text { nasal dryness / } \\
19 \% \text { eye dryness / } 12 \% \text { acne Other complaints: } 5 \% \text { skin lesions / } 5 \% \\
\text { impaired cognition / } 5 \% \text { epistaxis. }\end{array}$ \\
\hline
\end{tabular}

Thirteen studies were included in this review. All studies were observational; eleven were cross-sectional studies $6,8,17-25$, one was a prospective/cohort study ${ }^{26}$ and one was a retrospective study. ${ }^{27}$ Of those, two cross-sectional studies evaluated psychological outcomes, mental health disorders and associated factors among healthcare workers. One cross-sectional study investigated symptoms and causes of somatic symptom disorder (SSD) in Chinese nurses and all the other studies evaluated headaches associated with Personal Protective Equipment (PPE). Characteristics of included studies are presented on Table 1. 


\section{Analysis of the results}

A cross-sectional study at hospitals in Singapure and India was conducted to evaluate the association between psychological outcomes and physical symptoms among healthcare workers. The Depression, Anxiety and Stress Scale (DASS-21) was used to assess depression and anxiety and Impact of Events Scale-Revised (IES-R) was used for post-traumatic stress disorder (PTSD). It has been shown that out of the 906 healthcare workers who participated in the survey, $22.6 \%$ had previous comorbidities and the most frequent was migraine (9.6\%). A large number of participants (33.4\%) reported more than four physical symptoms, and the most frequent was headache (31.9\%). Regarding psychological outcomes, 5.3\% screened positive for moderate to very-severe depression, $8.7 \%$ for moderate to extremely-severe anxiety, $2.2 \%$ for moderate to extremely-severe stress, and $3.8 \%$ for moderate to severe levels of psychological distress. Depression, anxiety, stress, and PTSD were significantly associated with the presence of physical symptoms. ${ }^{22}$

A cross-sectional study assessed factors associated with anxiety/depression and determined prevalence of these disorders and the frequency of depression during the pandemic among neurosurgeons. Eight hundred neurosurgeons worldwide were recruited to respond online version of WHO Self-Reporting Questionnaire-20 that evaluated depression and anxiety. Out of 375 respondents from 52 countries, majority were from Asia ( $n=181,48.5 \%)$, consultants $(79 \%)$ or from low to middle-income countries (66\%). Almost 14\% showed anxiety/depression, 34\% felt tension, 33\% reported unhappiness, $25 \%$ had insomnia, and almost $20 \%$ reported headaches. Moreover, $14 \%$ had depression according to questionnaire scores. Anxiety and depression were more likely in those who did not receive guidance about self-protection from their institutions, did not feel safe with provided PPE, were exposed to a COVID. 19-positive colleague or whose families considered their workplace unsafe. ${ }^{19}$

Another cross-sectional study investigated symptoms and causes of somatic symptom disorder (SSD) in 140 nurses aged 20-50 years that worked at COVID-19 pneumonia intensive care units (ICU) in China. A questionnaire of symptoms was designed based on the International Classification of Functioning, Disability and Health (ICF) and 16 symptoms were evaluated. A questionnaire to evaluate possible risk factors was also designed and applied. Analysis was performed to cluster the symptoms and to find its risk factors. In 140 nurses, five major symptoms were chest discomfort and palpitation (31.4\%), dyspnea (30.7\%), nausea (21.4\%), headache (19.3\%), and dizziness (17.9\%). Symptoms were classified into three clusters: cluster $\mathrm{A}$ of breathing and sleep disturbances (dizziness, sleepiness, and dyspnea); cluster B of gastrointestinal complaints and pain (nausea and headache), and cluster C of general symptoms (xerostomia, fatigue, as well as chest discomfort and palpitation). Gender, sputum splash, urine/feces splash, and urine/feces clearance were risk factors for the occurrence of symptom clusters $(p<0.05)$. In cluster $\mathrm{A}$, urine/feces splash, gender, and sputum splash were related to symptoms; fall of protective glasses and urine/feces splash were related to cluster B; and urine/ feces splash and urine/feces clearance were related to symptoms of cluster C. ${ }^{6}$

Among 10 studies that evaluated headaches associated with PPE, physiological and adverse effects, tolerability of PPE usage, presence of PPE-headaches and associated factors, impacts of headache on personal health (both physical and mental health) and work performance were evaluated, as well as headache subtypes, appearance of "new headache", and exacerbation of pre-existing headache disorders. 8, 17, 18,20,21,23.27 Most were conducted in one country from Europe, North America, Africa or Asia and sample ranged from 72 to 2,711 participants. One was a cohort ${ }^{26}$, one was retrospective ${ }^{27}$, and all the others were cross-sectional studies. ${ }^{8,17,18,20,21,23-25}$

A work with small sample studied physiological effects and tolerability of PPE and N95 masks in healthcare workers. Significant differences in physiological parameters such as cardiac frequency, oxygen saturation, and pulsatility index were observed after PPE exchange in comparison to baseline values. Among adverse effects, headache was an important one. ${ }^{26}$

The largest study was conducted in over 90 countries of Europe, North America, and Asia and enrolled 2,711 participants. Headache was one of the reported adverse effects in $28 \%$ of respondents. ${ }^{18}$ Similarly, Shubhanshu and Singh $^{27}$ reported that headache was the most prevalent adverse effect of PPE in 423 healthcare professionals and frequency of this symptom was $23 \% .{ }^{27}$

Ong et al. (2020) evaluated 158 healthcare workers in Singapore. Of those, $29.1 \%$ had a pre-existing primary headache diagnosis and $81.0 \%$ developed 'de novo' PPEassociated headaches. Headache was bilateral in location and $87.5 \%$ described pain as pressure type. Over $70 \%$ classified pain as mild and $23.4 \%$ described associated symptoms as nausea and/or vomiting, photophobia, phonophobia, neck discomfort, and movement sensitivity. 
More than half of subjects $(52.3 \%)$ attributed usage of PPE as the cause for their headaches. Participants with a preexisting primary headache diagnosis and those working in the emergency department were more likely to develop 'de novo' PPE-associated headaches. Regarding impact of headaches, $91.3 \%$ of participants with pre-existing headache reported that PPE usage compromised control of their background headaches, which affected their level of work performance. ${ }^{17}$

Ramirez-Moreno and others (2020) evaluated 306 health professionals and $51.6 \%$ of those reported appearance of a new headache and $41.1 \%$ already had a headache (migraine or tension), which was modified in location, frequency, intensity and response to habitual analgesics in $83.1 \%$ subjects. In this study, occurrence of headache was associated with the use of a filter mask (FFP2 or KN95) and being a health worker or a nurse. Regarding self-perceived work stress, professionals with 'de novo' headache significantly had worse scores than those without headache.

The study of Haiiii et al. (2020) reported that $52.3 \%$ out of 155 professionals that participated in the survey had previous chronic headache and $62 \%$ had headache induced by the use of PPE. Headache was considered as "de novo" by $32.9 \%$ and $29 \%$ reported worsening of previous headache by the use of PPE. Headache induced by PPE occurred less or more than twice a week for $62.5 \%$ and $37.5 \%$, respectively. Frontal $(58.3 \%)$ and bi-temporal $(40.8 \%)$ areas were the most prevalent sites of headache. Working more than eight hours per shift during pandemic was correlated to 'de novo' headache and the profession of doctor was correlated to PPE aggravated headache. Type of mask was not correlated to 'de novo' headache neither to PPE aggravated headache occurrence. Respondents reported an impact on work-related quality of life due to PPE use during pandemic and experienced and $66.9 \%$ considered that their professional performance reduced. ${ }^{23}$

Among 241 health professionals evaluated in Pakistan, $21.1 \%$ had pre-existing headache, $28.2 \%$ showed recent onset headache and $28.2 \%$ reported 'de novo' headache. Most headaches were bilateral in location (69\%), with pressure/heaviness quality (45.5\%) and moderate intensity (66\%). Among participants, $41.2 \%$ believed that combined use of respiratory and eye protection was causing the 'de novo' headaches, while $22.4 \%$ attributed them to sleep deprivation. Presence of pre-existing headaches was associated with more susceptibility to PPE-induced headaches and age and department of activity may be additional risk factors. ${ }^{24}$
Rapisarda and others (2021) evaluated 383 healthcare providers in Italy. At baseline, $43.3 \%$ did not have headache, but $26.5 \%$ of those developed headache after 4 months. Out of $56.7 \%$ who reported pre-existing headaches, being migraine and tension-type headache the most frequent types, had worse symptoms mainly regarding frequency and duration of migraine attacks. ${ }^{25}$

One study evaluated cerebral hemodynamics during usage of N95 respirator mask alone or together with powered air-purifying respirators (PAPR) among 154 frontline healthcare workers. N95 mask was associated with headache in $80 \%$ of participants and N95 and N95 + PAPR lead to changes in cerebral hemodynamics. N95 masks caused a decrease in pulsatility index but its association to PAPR favors intracranial physiology as compared to N95 respirator mask alone. ${ }^{20}$

Swaminathan et al. (2020) studied the impacts of PPE on physical and mental well-being of 72 health professionals. Over $70 \%$ reported exhaustion when using PPE and $61.7 \%$ had headaches. Almost half of the participants $(47.3 \%)$ informed that PPE usage and its effects had negatively interfered with their performance. Moreover, $27.8 \%$ reported anxiety and $19.5 \%$ depression. ${ }^{8}$

\section{Discussion}

This review aimed to discuss evidence regarding COVID-19 pandemic effects on headache in healthcare workers. The thirteen included studies described physical symptoms and psychosocial impacts in healthcare workers during COVID-19 pandemic. Headache was one of the most frequent symptoms reported by the participants.

COVID-19 pandemic has had a huge impact on health systems all over the world. Frontline healthcare workers have been submitted to extremely stressful situations as previously described, which has led to the onset or worsening of physical and mental health symptoms. ${ }^{6}, 7,17,22,28-31$

All studies included in this review agree that the majority of healthcare workers develop some symptomatology related to the COVID-19 pandemic. The most common physical symptom was headache $6,17 \cdot 26$, especially those symptoms related to the PPE-usage. $8,17,18,20,21,23-27$

Moreover, greater psychological and physical fatigue, and sleep disturbances are also reported by individuals exposed to high workload. Psychological disorders, such as depression and insomnia are significantly associated with 
occupational stress. ${ }^{32.34}$ Although psychological reactions to stressful situations depend on individual vulnerability and neural mechanisms to stress response, coping strategies, and intolerance to uncertainty ${ }^{35}$, many studies have shown that COVID-19 pandemic has undoubtedly caused increased levels of psychological disorders. ${ }^{28}$ Among healthcare workers, psychological symptoms of distress, depression, anxiety, and insomnia commit 44 to $71 \%$ of individuals. 29,30 Moreover, presence of anxiety and depressive symptoms were associated with epidemiological issues, material and human resources, and personal factors. ${ }^{31}$ Different studies included in this review have shown that anxiety, depression, stress, and psychological distress are present in healthcare workers $8,19,22$ and those psychological factors were associated with appearance of "new headache" and exacerbation of pre-existing headache disorders. $8,17,18,20.27$

The physical and homeostasis' effects of using the PPE may also have influenced the presence of headache. Facemask and eye protection could exert mechanical forces and induce irritation of superficial sensory neurons at cranial and cervical regions. ${ }^{36}$ Ong et al. 2020 described the PPE-associated headache as a subtype of external-pressure headache. The prolonged mechanical force generates peripheral sensitization and activation of trigeminal cervical complex, which triggers headache attacks. This fact could not only explain the exacerbation of pre-existing primary headache, but also the 'de novo' PPE-associated headache. Moreover, this could lead and maintain central sensitization process, generating hyperalgesia and allodynia. ${ }^{25}$

The pathogenesis of PPE-associated headache could also involve hypoxemia and hypercapnia. A recent study showed that prolonged use of FFP2 mask led to a decrease in oxygen saturation of hemoglobin, an increase in heart rate and in facial temperature, which may lead health professionals to stress, fatigue, and headaches. ${ }^{37}$ High levels of carbon dioxide in the blood can also contribute to side effects such as dizziness, shortness of breath, and headaches. ${ }^{23}$

As headache was associated with increased duration of PPE, 15 minutes breaks every two hours of PPE usage have been suggested to lessen the deleterious effects. ${ }^{38}$ Spontaneous headache resolution within 60 minutes after removing PPE was reported. ${ }^{17}$

Although not within the scope of the studies at this stage, category of headaches deserves a discussion. It is possible that workers with previous history of a primary headache, especially migraine, suffer a strong impact of both, behavioral (sleep deprivation, stress, etc.) and physical stimulation (head and face pressure caused by the PPE), contributing to a significant worsening in the frequency and severity of migraine crises.

On the other hand, the increased muscle tension, possibly related to activation of masticatory muscles (teeth clenching and bruxism) may also stimulate new episoldes of pain in the head named Temporomandibular Disorders (TMD), which can have an overlap to the diagnostic classification of tensiontype headache. These statements, however, lack for evidence and deserve future investigations.

It is well known that headaches are associated with psychological stress, anxiety, depression, and sleep disorders. 11,39 The studies reviewed here have shown that physical overload by pandemic excessive workload have impacted the high prevalence of headache as a physical symptom as a consequence of stress, anxiety and PPE usage in healthcare professionals during COVID-19 pandemic. $6,17,22$ This has a huge impact on their well-being and work performance and on health system assistance. Institutional planning committees need to provide measures to minimize the negative impacts of work overload and PPE on their personnel. Healthcare administrators, policymakers, governments, and industry should raise efforts to address these issues. .,18 $^{8}$

\section{Conclusion}

The present review shows that COVID-19 pandemic has a significant negative impact on physical and mental health in healthcare workers. Headache has been associated with psychological stress, work overload, and PPE use during pandemic. Further studies are necessary to better investigate COVID-19 pandemic effects on the onset of different headache categories and other neurological conditions.

Conflict of Interest: The authors declare no conflict of interest.

Authors' Contributions: JGAJR and FTSN performed data collection and formal analysis, discussed the results, and wrote the original manuscript. JSB and PCC conceived the idea of the study, discussed the results, performed supervision, and commented on the manuscript. CMAL conceived the idea for the study, collected and analyzed data, supervised the study, wrote and reviewed manuscript.

João Gabriel de Azevedo José Romero

https://orcid.org/0000-0002-3891-8648

Franklin Teixeira de Salles-Neto

https://orcid.org/0000-0001-5288-7203

Juliana Stuginski-Barbosa

https://orcid.org/0000-0002-7805-5672 
Paulo César Rodrigues Conti

https://orcid.org/0000-0003-0413-4658

Camila Megale Almeida-Leite

https://orcid.org/0000-0003-2694-8521

\section{References}

1. Lu H, Stratton CW and Tang YW. Outbreak of pneumonia of unknown etiology in Wuhan, China: The mystery and the miracle. J Med Virol 2020;92(4):401402 Doi:10.1002/jmv.25678

2. Rothan HA and Byrareddy SN. The epidemiology and pathogenesis of coronavirus disease (COVID-19) outbreak. J Autoimmun 2020;109:102433 Doi:10.1016/j.jaut.2020.102433

3. loannidis JPA. Coronavirus disease 2019: The harms of exaggerated information and non-evidence-based measures. Eur J Clin Invest 2020;50(4):e13222 Doi: 10.1111 /eci.13222

4. Peng PWH, Ho PL and Hota SS. Outbreak of a new coronavirus: what anaesthetists should know. $\mathrm{Br}$ J Anaesth 2020;124(5):497-501 Doi:10.1016/i. bja.2020.02.008

5. Sinanović $O$, Muftić $M$ and Sinanović S. COVID-19 Pandemia: Neuropsychiatric Comorbidity and Consequences. Psychiatr Danub 2020;32(2):236-244 Doi: 10.24869/psyd.2020.236

6. Yifan T, Ying L, Chunhong G, Jing S, Rong W, Zhenyu L, ... Peihung L. Symptom Cluster of ICU Nurses Treating COVID-19 Pneumonia Patients in Wuhan, China. J Pain Symptom Manage 2020;60(1):e48-e53 Doi:10.1016/i. ipainsymman.2020.03.039

7. Kleinpell R, Ferraro DM, Maves RC, Kane Gill SL, Branson R, Greenberg S, . . Kaplan LJ. Coronavirus Disease 2019 Pandemic Measures: Reports From a National Survey of 9,120 ICU Clinicians. Crit Care Med 2020;48(10):e846-e855 Doi:10.1097/ ccm.0000000000004521

8. Swaminathan R, Mukundadura BP and Prasad S. Impact of enhanced personal protective equipment on the physical and mental well-being of healthcare workers during COVID-19. Postgrad Med J 2020;Doi:10.1136/ postgradmedj-2020-139150

9. Mongini F, Ciccone G, Deregibus A, Ferrero Land Mongini T. Muscle tenderness in different headache types and its relation to anxiety and depression. Pain 2004;112(12):59-64 Doi:10.1016/i.pain.2004.07.025

10. Juang KD, Wang SJ, Fuh JL, Lu SR and Su TP. Comorbidity of depressive and anxiety disorders in chronic daily headache and its subtypes. Headache 2000;40(10):818823 Doi:10.1046/j.1526-4610.2000.00148.x
11. Beghi E, Bussone G, D'Amico D, Cortelli P, Cevoli $S$, Manzoni GC, . . Salvi S. Headache, anxiety and depressive disorders: the HADAS study. I Headache Pain 2010;1 1(2):141-150 Doi:10.1007/s10194-010$0187-2$

12. Breslau N, Schultz LR, Stewart WF, Lipton RB, Lucia VC and Welch KM. Headache and major depression: is the association specific to migraine? Neurology 2000;54(2):308-313 Doi:10.1212/wnl.54.2.308

13. Smitherman TA, Kolivas ED and Bailey JR. Panic disorder and migraine: comorbidity, mechanisms, and clinical implications. Headache 2013;53(1):23-45 Doi: $10.1111 /$ head. 12004

14. Pearl TA, Dumkrieger G, Chong CD, Dodick DW and Schwedt TJ. Impact of Depression and Anxiety Symptoms on Patient-Reported Outcomes in Patients With Migraine: Results From the American Registry for Migraine Research (ARMR). Headache 2020;60(9):1910-1919 Doi:10.1111/head.13911

15. McWilliams LA, Goodwin RD and Cox BJ. Depression and anxiety associated with three pain conditions: results from a nationally representative sample. Pain 2004;111/12):77-83 Doi:10.1016/i.pain.2004.06.002

16. Kropp P, Egli G and Sándor PS. Tension-type headache introduction and diagnostic criteria. Handb Clin Neurol 2010;97:355-358 Doi:10.1016/s00729752(10)97028-0

17. Ong JJY, Bharatendu C, Goh Y, Tang JZY, Sooi KWX, Tan YL, ... Sharma VK. Headaches Associated With Personal Protective Equipment - A Cross-Sectional Study Among Frontline Healthcare Workers During COVID-19. Headache 2020;60(5):864-877 Doi:10.1111/ head.13811

18. Tabah A, Ramanan M, Laupland KB, Buetti N, Cortegiani A, Mellinghoff J, ... De Waele JJ. Personal protective equipment and intensive care unit healthcare worker safety in the COVID-19 era (PPE-SAFE): An international survey. J Crit Care 2020;59:70-75 Doi:10.1016/i. icrc.2020.06.005

19. Sharif S, Amin F, Hafiz M, Benzel E, Peev N, Dahlan RH, . .. Vaishya S. COVID 19-Depression and Neurosurgeons. World Neurosurg 2020;140:e401-e410 Doi:10.1016/j.wneu.2020.06.007

20. Bharatendu C, Ong JJY, Goh Y, Tan BYQ, Chan ACY, Tang JZY, . . . Sharma VK. Powered Air Purifying Respirator (PAPR) restores the N95 face mask induced cerebral hemodynamic alterations among Healthcare Workers during COVID-19 Outbreak. IJ Neurol Sci 2020;417:1 17078 Doi:10.1016/i.jns.2020.117078

21. Ramirez-Moreno JM, Ceberino D, Gonzalez Plata A, Rebollo B, Macias Sedas P, Hariramani R, ... Constantino AB. Mask-associated 'de novo' headache in healthcare 
workers during the COVID-19 pandemic. Occup Environ Med 2020;Doi:10.1136/oemed-2020-106956

22. Chew NWS, Lee GKH, Tan BYQ, Jing M, Goh Y, Ngiam $\mathrm{NJH}$, . . . Sharma VK. A multinational, multicentre study on the psychological outcomes and associated physical symptoms amongst healthcare workers during COVID-19 outbreak. Brain Behav Immun 2020;88:559565 Doi:10.1016/i.bbi.2020.04.049

23. Haiiii A, Aasfara J, Khalis M, Ouhabi H, Benariba F, Jr. and El Kettani C. Personal Protective Equipment and Headaches: Cross-Sectional Study Among Moroccan Healthcare Workers During COVID-19 Pandemic. Cureus 2020;12(12):e12047 Doi:10.7759/cureus. 12047

24. Zaheer R, Khan M, Tanveer A, Farooq A and Khurshid Z. Association of Personal Protective Equipment with De Novo Headaches in Frontline Healthcare Workers during COVID-19 Pandemic: A CrossSectional Study. Eur J Dent 2020;14(S 01):S79-s85 Doi:10.1055/s-0040-1721904

25. Rapisarda L, Trimboli M, Fortunato F, De Martino A, Marsico O, Demonte G, ... Gambardella A. Facemask headache: a new nosographic entity among healthcare providers in COVID-19 era. Neurol Sci 2021;42(4): 12671276 Doi:10.1007/s 10072-021-05075-8

26. Choudhury A, Singh M, Khurana DK, Mustafi SM, Ganapathy U, Kumar A and Sharma S. Physiological Effects of N95 FFP and PPE in Healthcare Workers in COVID Intensive Care Unit: A Prospective Cohort Study. Indian J Crit Care Med 2020;24(12):1169-1173 Doi:10.5005/ip-journals-10071-23671

27. Kumar $\mathrm{S}$ and Singh A. Prolonged Use of $\mathrm{n} 95$ Mask a Boon or Bane to Healthcare Workers During Covid-19 Pandemic. Indian J Otolaryngol Head Neck Surg 2021;1-4 Doi:10.1007/s12070-021-02396-0

28. Salari N, Hosseinian-Far A, Jalali R, Vaisi-Raygani A, Rasoulpoor S, Mohammadi M, ... Khaledi-Paveh B. Prevalence of stress, anxiety, depression among the general population during the COVID-19 pandemic: a systematic review and meta-analysis. Global Health 2020; 16(1):57 Doi: 10.1 186/s1 2992-020-00589-w

29. Ng QX, De Deyn M, Lim DY, Chan HW and Yeo WS. The wounded healer: A narrative review of the mental health effects of the COVID-19 pandemic on healthcare workers. Asian J Psychiatr 2020;54:102258 Doi:10.1016/i.ajp.2020.102258
30. Lai J, Ma S, Wang Y, Cai Z, Hu J, Wei N, ... Hu S. Factors Associated With Mental Health Outcomes Among Health Care Workers Exposed to Coronavirus Disease 2019. JAMA Netw Open 2020;3(3):e203976 Doi:10.1001/jamanetworkopen.2020.3976

31. Braquehais MD, Vargas-Cáceres $S$, Gómez-Durán E, Nieva G, Valero S, Casas M and Bruguera E. The impact of the COVID-19 pandemic on the mental health of healthcare professionals. Qjm 2020;Doi:10.1093/ qimed/hcaa207

32. Ganster DC and Rosen CCJJom. Work stress and employee health: A multidisciplinary review. J Manage 2013;39(5):1085-1122 Doi: $10.1177 / 0149206313475815$

33. Marchand A, Bilodeau J, Demers A, Beauregard N, Durand $P$ and Haines VY, 3rd. Gendered depression: Vulnerability or exposure to work and family stressors? Soc Sci Med 2016;166:160-168 Doi:10.1016/i. socscimed.2016.08.021

34. Dong $H$, Zhang $Q$, Sun Z, Sang F and Xu Y. Sleep problems among Chinese clinical nurses working in general hospitals. Occup Med (Lond) 2017;67(7):534539 Doi:10.1093/occmed/kqx124

35. Ebner $\mathrm{K}$ and Singewald $\mathrm{N}$. Individual differences in stress susceptibility and stress inhibitory mechanisms. Curr Opin Behav Sci 2017; 14:54-64 Doi:10.1016/j. cobeha.2016.11.016

36. Krymchantowski AV. Headaches due to external compression. Curr Pain Headache Rep 2010; 14(4):321324 Doi:10.1007/s 1 1916-010-0122-x

37. Scarano A, Inchingolo F, Rapone B, Festa F, Tari SR and Lorusso F. Protective Face Masks: Effect on the Oxygenation and Heart Rate Status of Oral Surgeons during Surgery. Int J Environ Res Public Health 2021;18(5): 2363 Doi:10.3390/ijerph 18052363

38. Jose S, Cyriac MC and Dhandapani M. Health Problems and Skin Damages Caused by Personal Protective Equipment: Experience of Frontline Nurses Caring for Critical COVID-19 Patients in Intensive Care Units. Indian J Crit Care Med 2021;25(2): 134-139 Doi:10.5005/ipjournals-10071-23713

39. Martin PR. Stress and Primary Headache: Review of the Research and Clinical Management. Curr Pain Headache Rep 2016;20(7):45 Doi:10.1007/s1 1916016-0576-6 